\title{
1 The maternal environment determines the timing of germination in
}

\section{Pinus pinaster}

3

4 César Cendán ${ }^{1}$, Luis Sampedro ${ }^{2}$, Rafael Zas ${ }^{1 *}$

$5{ }^{1}$ Misión Biológica de Galicia (MBG-CSIC), Apdo. 28, 36080 Pontevedra, Galicia,

$6 \quad$ Spain

$7 \quad{ }^{2}$ Centro de Investigación Forestal de Lourizán - Unidad Asociada MBG-CSIC, Apdo. 8 127, 36080 Pontevedra, Galicia, Spain.

9

$10 *$ Corresponding author: $\quad$ rzas@mbg.csic.es

11

12

13

14

15

16

17

18

19 Running title: Maternal effects in pine germination

20 Type of article: regular paper

21 Number of total pages (including references, figures and tables): 27

22 Number of words (Introduction, Material and Methods, Results, Discussion and

23 References): 5584

24 Number of Tables: 3

25 Number of Figures: 2
Phone Number: +34986854800

Fax Number: +34986841362 


\section{Abstract}

27 Optimizing the germination timing is crucial for the establishment of new generations.

28 We hypothesized that environmental maternal effects may be relevant in the fine tuning

29 of this trait in a long-lived Mediterranean model tree. We analyzed the influence of

30 maternal genotype, maternal environment and their interaction on the germination

31 success and germination phenology of 8725 Pinus pinaster seeds collected from

32 genotypes clonally replicated in two contrasting environments. Besides maternal genetic

33 effects, the maternal environment significantly affected both the percentage and the

34 timing of germination. Seeds from the more favourable environment germinated 7.5

35 days earlier and showed higher germination rate $(0.93 \pm 0.01$ vs $0.85 \pm 0.03)$. Seed

36 weight significantly influenced germination time, but seed weight differences between

37 maternal environments were not enough to explain this form of transgenerational

38 plasticity. The effect of the maternal environment varied depending on the genotype,

39 indicating that genetic variation in the sensitivity to the maternal environment in this

40 pine species does exist.

42 Highlights: $>$ The maternal environment influences both the percentage and germination time $>$ Favourable maternal environment favoured and speeded pinion germination $>$ Differences were not explained by seed weight effects $>$ Environmental maternal effects were genetically variable

47 Key-words: Adaptive traits; Carryover effects; Conifers; Forestry; Long-lived plants; 48 Maritime pine; Maternal environmental effects; Seed weight; Seed size;

49 Transgenerational plasticity 


\section{Introduction}

53 Optimizing the timing of germination is vital for the establishment of an individual, especially in areas with strong seasonal variability (Baskin and Baskin, 1998; Castro, 2006). Among other limitations, germinating too early may expose the immature seedling to late frost injuries, whereas delaying germination may reduce the early competitive ability of the resulting offspring (Donohue et al., 2010). Plant populations have evolved to fine tune the timing of germination accordingly to these and other selective pressures. Environmental gradients within the distribution range of a plant species have commonly led, thus, to large among-population differentiation in this adaptive trait (see references in Baskin and Baskin, 1998; Donohue et al., 2010; Wagner and Simons, 2009).

Additive genetic variation within populations provides the fuel for adapting the timing of germination to the current environmental conditions. In addition to this, there is emerging evidence that environmental maternal effects are also relevant influencing this process (Donohue, 2009; Donohue et al., 2010; Tielborger and Petru, 2010). Environmental maternal effects are defined as the direct contribution of the maternal environment to the offspring phenotype, irrespective of the chromosomal contribution of the parents (Roach and Wulff, 1987). In angiosperms, there is increasing evidence that environmental maternal effects affects both germination percentage (Alboresi et al., 2005; Donohue, 2009; Figueroa et al., 2010; Tielborger and Petru, 2010) and germination phenology (Biere, 1991; Lacey, 1996). For instance, in resource limiting environments, seeds of semi-arid Mediterranean plant species developed in favourable years were found to have higher proportion of dormant seeds (Tielborger and Petru, 2010). Delaying the germination of a fraction of the seed yield may help to reduce 
77 in following unfavourable years (Tielborger and Petru, 2010). Environmental factors

78 such as photoperiod and temperature during seed maturation have also been found to determine the environmental conditions needed to broke dormancy in Arabidopsis thaliana, and therefore significantly modulate germination timing (Boyko et al., 2010; Donohue et al., 2008). Moreover, it is well known that the environmental conditions where the mother plant grows may largely influence the size of the seeds, which in turn may influence germination timing and success (Castro et al., 2006). Identifying the environmental, genetic and epigenetic mechanisms involved in the transmission of maternal environmental effects through the seeds is important to understand their ecological function and adaptive value. This field is becoming a prolific research line in angiosperms (Boyko and Kovalchuk, 2011; Gehring et al., 2009; Mirouze and Paszkowski, 2011; Mosher and Melnyk, 2010) but available information for long-lived woody species such as gymnosperms is much more limited (Dolgosheina et al., 2008; Yakovlev et al., 2010) In conifers, the maternal environment is known to influence the offspring frosthardiness (Johnsen et al., 1996; Lindgren and Wei, 1994), but there are only few examples of significant environmental maternal effects on germination phenology

94 (Stoehr et al., 1998). Curiously, however, certain particularities of the reproduction in gymnosperms could favour their sensitivity to environmental maternal effects. In conifers, both the seed coat and the endosperm had maternal origin whereas in angiosperms both parents genetically contribute to form the endosperm (Linkies et al., 2010). Additionally, the period during which the seed remain connected to the mother is, in some genera such as Pinus, remarkably large, lasting up to two years in Maritime pine (Pinus pinaster Ait.) and even more in other species. Although the underlying mechanisms involved in the transmission of environmental maternal effects are largely 
102 unknown, they are likely activated during this period (Donohue et al., 2008; Lacey et 103 al., 1997; Roach and Wulff, 1987).

104 The main objective of this paper was to evaluate the influence of the maternal 105 environment on the germination timing of Pinus pinaster. This pine species is an 106 emblematic Mediterranean forest tree that occupies more than 4 million ha in southwest

107 Europe and north Africa, and it is becoming a model species for genetic and ecological 108 studies in the Mediterranean region (González-Martínez et al., 2004). We followed the 109 germination timing of pre-weighted seeds collected from several genotypes clonally

110 replicated in two contrasting environments, one with favourable conditions for the

111 development of this pine species (in terms of growth and reproduction rate), and the

112 other one with less favourable conditions (see Table 1). Our experimental design

113 allowed to separate and quantify the influence of the maternal genotype, the maternal 114 environment and their interaction, providing a quantification of the relative contribution

115 of genetic and epigenetic effects on both the germination success and the germination

116 timing, two relevant life-history traits that represent the main change within a plant

117 cycle, the switch from adult to offspring.

119 2. Material and methods

\section{$120 \quad$ 2.1. Site location and plant material}

121 Seed material was collected from two clonal seed orchards with exactly the same

122 genetic material and experimental design but contrasting site qualities. Both seed 123 orchards belong to the Galician Tree Breeding Program (Consellería do Medio Rural, 124 Xunta de Galicia) and include 116 unrelated $P$. pinaster genotypes. These genotypes 125 were selected in natural stands or mature plantations within the coastal area of Galicia 126 (NW Spain, provenance '1a. Noroeste Litoral' sensu Alía et al. (1996)). Within each 
127 stand, individual trees were mass selected for their superior growth, stem form and

128 branching habit by comparing its phenotype with that of the surrounding trees (see Zas

129 et al., 2004 for details). Scions were collected in each selected tree using climbing tools

130 and grafted on two-year old seedlings (height $\sim 80 \mathrm{~cm}$, basal diameter $\sim 1.5 \mathrm{~cm}$ ) by

131 replacing the terminal bud. Each genotype was clonally replicated by grafting in 10

132 individual trees (ramets) within each site. The experimental layout in each site was a

133 randomized block design with 10 blocks and one ramet of each genotype per block. The

134 favourable seed orchard (Sergude, $42.82^{\circ} \mathrm{N}, 8.45^{\circ} \mathrm{W}$ ) is located in a high quality site

135 for $P$. pinaster development, with mild temperatures, adequate moisture all over the

136 year, and well drained and deep soil (Table 1). The other seed orchard (Monfero, $43.52^{\circ}$

$137 \mathrm{~N}, 7.93^{\circ} \mathrm{W}$ ) is located in the top of a hillside on a site especially harmful for $P$. pinaster.

138 Pine growth and reproduction in this site are strongly limited by low winter and spring

139 temperatures, extreme wind exposure, and water-logging and thin soils (Table 1). In

140 average, individual pine growth (measured as the annual increment in basal area at

141 breast height) was more than eight times higher in Sergude than in Monfero (Table 1).

142 The reproduction effort (both at a common age and at a common tree size) was also

143 much higher in Sergude. Based on the extreme differences in growth and reproduction

144 rates we will refer to Sergude as the favourable maternal environment, and to Monfero

145 as the stressful maternal environment.

\section{2.2. Cone and seed sampling, processing and sowing}

148 Ten genotypes, randomly selected among the 116 genotypes included in the seed

149 orchards, were used in this study. In January 2007, four to six ramets of each of these

150 genotypes were selected for sampling within each seed orchard. In each ramet, three to

151 four cones were randomly selected within the tree at the stage of flowers (March 2007), 
152 adequately labelled and allowed to be open-pollinated during spring 2007. In January

1532009 , after the regular maturation time for this species (two seasons), all the cones were 154 carefully collected using ladders and climbing tools. Total sample size was 377 cones.

155 Diameter at breast height was measured in all mother trees.

156 Cones were air dried for a few weeks and then oven-dried $\left(7 \mathrm{~d}\right.$ at $\left.35^{\circ} \mathrm{C}\right)$ to induce

157 opening. After this time, cones were weighed with a precision scale $(0.001 \mathrm{~g})$ and all the

158 seeds were removed and stored in PET vials at $4{ }^{\circ} \mathrm{C}$. For each individual cone, empty

159 seeds were separated by decantation in cold water for some seconds, where empty seeds

160 remained floating at the surface. Empty and filled seeds were immediately oven-dried

161 again at $35{ }^{\circ} \mathrm{C}$ for seven days, and then the number and total weight of seeds per cone

162 were recorded. Twenty four filled seeds per cone were randomly selected, individually

163 weighed $(0.0001 \mathrm{~g})$, identified by their position in 96 wells microplates and stored at 4

$164{ }^{\circ} \mathrm{C}$. These identified seeds were individually sown on sterilized vermiculite $(0.5-2.0$

165 mm coarse), using 96 wells sowing trays with $9 \mathrm{~cm}$ tall wells. Trays were moisturized

166 and disposed at random inside a glass greenhouse in October 2009 at temperatures

167 fluctuating in the range of $22 \pm 4^{\circ} \mathrm{C}$. Germination was individually assessed every

168 second or third day during three months. Total sample size was 8990 identified seeds of 169 known individual seed weight.

\subsection{Statistical analyses}

172 The effects of design factors on the percentage of filled seeds and the germination

173 percentage per cone were analyzed with a generalized linear mixed model using the 174 PROC-GLIMMIX procedure of the SAS System, assuming a binomial residual 175 distribution. A hierarchical model with two levels of nested experimental units (ramets 176 and cones) was considered (Littell et al., 2006). This model includes the fixed effect of 
177 the maternal environment (the two twin seed orchards with contrasting site qualities),

178 the random effect of the maternal genotype (the 10 genotypes clonally replicated in each

179 seed orchard), and the random interaction between both factors, which represents the

180 genetic variation in the transmission to the progeny of environmental maternal effects.

181 The model also include the effect of blocks nested within each seed orchard, which

182 accounted for the environmental variation within each seed orchard, and the random

183 effect of ramets, accounting for micro-environmental variation at scales lower than the

184 block size and other phenotypic effects of the ramets such as the effect of the root

185 genotype in which the genotypes were grafted, ontogeny, biotic interactions, etc.

186 Measures from different cones within the same ramet were considered as a within-

187 subject factor (Littell et al., 2006). As cones were open-pollinated, any environmental

188 and genetic paternal effects would be included into the residual term. Diameter at breast

189 height of each tree was also included as a fixed covariate in this model in order to

190 account for possible allometric effects, but it was removed because it was not significant

191 and did not improve the resolution of the model.

192 The effects of design factors on germination time were analyzed using a linear

193 mixed model with the PROC-MIXED procedure of the SAS System fitting a

194 hierarchical model similar to those used to solve a split-split design with three levels of

195 nested experimental units: ramets, cones and seeds (Littell et al., 2006). Both, values

196 within a given cone, and values from different cones within a ramet were dependent

197 measures within the same subject (cone or ramet, respectively). Besides the factors

198 included in the former model and described above, the model also included the random

199 effect of cones, the covariation of the germination time with the individual seed weight,

200 and the interaction of the seed weight with the maternal environment, which accounted

201 for the possible variation between environments in the seed weight covariation. Both 
202 fixed covariates were highly significant and clearly improved the model. Diameter of

203 the mother tree and cone weight were included as covariates in a former version of this

204 model, but then removed as they did not improve the likelihood of the model. Both the

205 ramet and cone effects were considered within-subject random effects, thus conforming

206 together with the residual error term, the three experimental units of this hierarchical

207 model (ramet, cone and seed).

208 The statistical significance of the variance components for each random factor in 209 both statistical models was assessed using likelihood or pseudo-likelihood ratio tests

210 (Littell et al. 2006), where the differences in two times the log-likelihood of the models

211 including and excluding that random factor are distributed as one tailed $\chi^{2}$, with one

212 degree of freedom.

213 Cumulative germination over time was modelled by fitting exponential and 214 Gompertz models using nonlinear regression procedures in SAS. The time needed to 215 reach the inflexion point (i.e. the time needed for germination of the $50 \%$ of the sowed 216 seeds) was used to quantitatively compare the timing of germination between both 217 environments.

\section{3. Results}

220 The maternal environment significantly affected both the percentage of germination

221 (Table 2) and the emergence time (Table 3). Specifically, seeds from trees of the high 222 quality site germinated more successfully $(0.927 \pm 0.013$ and $0.854 \pm 0.029$ in the 223 favourable and unfavourable maternal environments respectively) and around seven 224 days earlier than those from the unfavourable maternal environment (Figure 1). The percentage of filled seeds did not significantly differ between the two maternal 
environments (Table 2, $0.927 \pm 0.01$ and $0.922 \pm 0.01$ in the favourable and unfavourable maternal environments, respectively).

Germination time was genetically variable (Table 2), with average emergence time varying among maternal genotypes from 23.6 to 39.0 days since sown. The significant genotype by environment interaction also revealed that pine families varied

231 in their ability to express maternal environments effects in their germination time (Table 2). Comparison of variance components for the $G$ and $G \times E$ effects indicates that the variation among genotypes in this form of transgenerational plasticity was even higher

234 than the genetic variation in the average germination time (Table 2). Differences

235 between environments in the timing of germination ranged from 0.6 days for pinions of genotype G1 to 14.5 days for pinions of genotype G9 (Figure 2b). Germination time of seeds from the favourable maternal environment was shorter for all the studied genotypes (Figure 2b).

Percentage of filled seeds also significantly varied among maternal genotypes, but no genetic variation and just marginally significant $\mathrm{G} \times \mathrm{E}$ interaction were observed

241 for the germination percentage (Table 2). While seeds from the favourable environment 242 germinated earlier in all cases, the effect of the maternal environment in the percentage 243 of germination showed contrasting trends, depending on the family (Figure 2a).

244 Germination time significantly covariated with seed weight (Table 2), with 245 heavier seeds germinating earlier. The significant $\mathrm{SW} \times \mathrm{E}$ interaction revealed that the 246 dependence of the timing of germination on the seed weight was not the same for the 247 two maternal environments (Table 2). The slopes of the covariation between seed 248 weight and germination time significantly differed between the two environments. The covariation for seeds from the unfavourable environment (slope in Monfero $=-0.187 \pm$ 0.021) was steeper than that for seeds from the favourable environment (slope in 
251 Sergude $=-0.026 \pm 0.017$ ). This result indicates that the effect of seed weight on

252 germination time was more pronounced in the unfavourable environment.

\section{Discussion}

255 Our results showed that the maternal environment had a strong influence on both the 256 germination viability and the timing of germination of $P$. pinaster pinions. Seeds from

257 the stressful maternal environment germinated later, and the proportion of seeds that remained ungerminated at the end of the experiment was higher for this maternal environment. There is growing evidence that maternal effects are involved in the expression of key characters controlling the adaptation of populations to environmental

261 conditions (Bossdorf et al., 2009; Donohue, 2009; Donohue et al., 2008; Donohue et al., 262 2010; Richards et al., 2010; Tarutani et al., 2010). Previous studies have also identified environmental maternal effects as a significant factor explaining the variation in germination timing and dormancy in different plant species (Biere, 1991; Donohue et al., 2005; Stoehr et al., 1998; Teixeira et al., 2009; Tielborger and Petru, 2010). Particularly, Picea glauca seeds from mother trees grown at colder conditions have been shown to germinate earlier and in greater proportion, and the resulting seedlings were more frost hardy (Stoehr et al., 1998). These last results contrast with the results reported here, in which seeds from mother trees grown in the colder environment germinated later and in lower proportion. This discrepancy may arise because the environmental factors that more critically limit seedling performance differ between the two studies. For example, under boreal climates, the plants may benefit from starting its development soon, as they would have more chance to exploit the short growing season

274 (Bevington, 1986). Furthermore, differences between the maternal environments in the

275 Stoehr et al. (1998) study also include differences in maternal photoperiod, which has 
276 been reported to modulate offspring germination time (Donohue et al., 2005). Seeds

277 from the northern location were developed under shorter photoperiods, and thus could 278 tend to germinate earlier than seeds from the southern location when planted in a 279 common environment. In our case, latitude differences between the two maternal 280 environments were minimal and the photoperiod was almost the same in both sites.

281 Our results seem to agree with the idea that the delay in the germination of the 282 seeds collected in the colder environment can help the offspring to 'escape' from late 283 frost damage. This would be in the same line that several studies in boreal conifers that 284 have reported that environmental maternal effects are mechanisms for cold adaptation 285 (Andersson, 1994; Johnsen et al., 2005; Lindgren and Wei, 1994; Webber et al., 2005). 286 Johnsen et al. (2005) observed that mother trees of Picea abies subjected to photoperiod 287 and temperature conditions of higher latitudes during embryo development and seed 288 maturation lead to offspring phenotypes with biological rhythms adapted to cold. However, it should be noted here that the environmental differences between the two maternal environments of our study are not limited to the temperature regime, but also

291 include large differences in other characteristics such as edaphic properties or wind 292 exposure that have strong influences in primary productivity and tree growth (Table 1). 293 All these environmental factors are also known to be potential drives of 294 transgenetational plastic responses (e.g. Latzel et al., 2010). Besides, adaptation to late 295 spring frosts is probably not the main driver of the transmission of maternal effects 296 under Mediterranean conditions, although it cannot be discarded because of the 297 biogeographic history of this species during glacial periods.

Although our results suggested strong environmental maternal effects on 299 germination time and viability, different male parent donors in the two environments 300 may have also contributed to genetically differentiate the seeds in the two maternal 
environments. Several reasons led us to think, however, that environmental maternal

302 effects prevail upon male genetic effects. Firstly, the most plausible source of parental 303 differences may arise from contamination by foreign pollen, which is very unlikely, as 304 both environments are controlled seed orchards, i.e. plantations designed for seed 305 production that are established further away from other $P$. pinaster stands. Pollen 306 introgression is, thus, assumed to be low. Secondly, both seed orchards include exactly 307 the same genetic material and have the same spatial designs, so spatial differences in the 308 male gametic contribution within each plantation are likely to be low. Thirdly, although 309 variation in reproductive phenology and allocation could contribute in part to imbalance 310 the parental contributions within each orchard (Zas et al., 2003) the reproductive effort 311 of $P$. pinaster, although plastic, has been shown to present low genotype $\times$ environment 312 interaction (Santos-del-Blanco et al., 2010), so the average pollen contribution in both 313 seed orchards is expected to be similar. Finally, and more importantly, the seed tissues 314 that most influence germination (the coat and the endosperm) are completely maternal 315 in gymnosperms (Linkies et al., 2010). Specifically, all hormones and provisioning 316 transcripts regulating germination are directly transmitted from the mother 317 (Nakabayashi et al., 2005). Indeed, it is widely assumed that the female genetic 318 contribution has much more influence on germination than the male contribution 319 (Baskin and Baskin, 1998; Donohue, 2009; Roach and Wulff, 1987). Despite all these 320 convincing explanations about the relevance of environmental maternal effects on the 321 observed differences in germination between the two maternal environments, further experiments with control-pollinated seeds are necessary to confirm the results presented 323 here.

The contrasted climatic conditions between the two maternal environments may 325 have also favoured differences in cone and pinion maturation. The observed differences 
326 in germination time of the seeds from the two environments could thus be explained, at

327 least in part, by differences in seed maturity between environments. However full 328 embryo maturation in Pinus is typically complete in the second autumn after 329 fertilization (Keeley and Zedler, 1996). Particularly, P. pinaster embryos in Portugal, 330 not far from our seed orchards, has been reported to be full matured at the end of the 331 second summer (Miguel et al., 2004). Because we harvested the cones in January, long 332 after the complete maturation of the seeds, differences in embryo maturation between 333 the two maternal environments in our study can be discarded. Another confounding factor that could have differentially affected the 335 germination of the seeds from the two maternal environments is the possible differential 336 effect of the rootstocks in the two seed orchards. The genotype of the rootstock is 337 known to potentially influence the performance of the grafted scion, affecting, among 338 others, its growth and reproduction, disease resistance, drought tolerance, or fruit 339 quality (reviewed for conifers by Jayawickrama et al., 1991). Particularly, because 340 rootstock can modulate the genetic expression patterns of the scions (Jensen et al., $3412010)$ it could potentially affect the epigenetic transmission of maternal effects through 342 the seeds. However, the effect of the rootstock is commonly only relevant when comparing very different rootstock genotypes, even of different species (Jayawickrama

344 et al., 1991). In our case, we used as rootstocks relatively homogeneous commercial 345 material from the same provenance. Rootstock effects are, thus, expected to be low. 346 Furthermore, the same rootstock material was used in the two seed orchards so we can 347 assume that rootstock effects are unlikely contributing to differentiate the seeds from the 348 two maternal environments.

349 According to Galloway and Etterson (2007), maternal effects are adaptive if i) 350 the maternal environment influences the offspring phenotype, ii) the effect of the 
351 maternal environment is genetically based, and iii) the transgenerational effects enhance

352 the fitness of the progeny under environments similar to the maternal environment. Our 353 results support with enough empirical evidence the first of these arguments, i.e. the 354 maternal environment does significantly influence the germination of $P$. pinaster seeds.

355 Additionally, the significant and large $\mathrm{G} \times \mathrm{E}$ interaction supports that within population genetic variation in the offspring sensitivity to the maternal environment does exist, and

357 thus, these plastic responses can evolve enhancing the adaptation of populations to environmental variation. Results reported here do not allow, however, to determine whether the observed maternal effects increase offspring fitness. Further reciprocal

360 transplant experiments are needed to demonstrate the adaptive value of the observed maternal effects (e.g. Galloway and Etterson, 2007).

363 Ramirez-Valiente et al., 2009) and it is known to be strongly influenced by the maternal

364 environment (Linkies et al., 2010). Many studies have found that the significant effect

365 of the maternal environment on germination time was, in fact, driven by differences on 366 seed weight (reviewed in Castro et al., 2006). In our case, the germination time 367 significantly covariated with seed weight, with bigger seeds tending to germinate earlier. This trend, which was more apparent for the stressful environment, has been 369 previously observed, and interpreted in terms of the increased chance of embryo 370 development within seeds with higher reserves (Castro et al., 2006). Nevertheless, 371 although seed weight appeared to affect germination, differences in the timing of 372 germination between seeds obtained in the two maternal environments were not only 373 due to differences in the seed weight betwen the two sites. The effect of the maternal 374 environment remained highly significant even when the statistical model properly 375 accounted for the seed weight covariation. Our results suggest, thus, that other 
376 mechanisms not related to seed size must be involved in the transmission of the

377 observed maternal effects regarding germination traits. Nowadays, there is increasing 378 evidence that epigenetic mechanisms, including changes in the frequency of 379 homologous recombination, changes in DNA methylation patterns, micro and small 380 RNAs, transposons and histone modifications, are involved in the transgenerational 381 plastic responses to stress conditions (Boyko and Kovalchuk, 2011; Mirouze and 382 Paszkowski, 2011). Additionally, direct environmental effects on the accumulation of 383 metabolites, proteins and/or mRNAs in the seeds can also play a significant role in the 384 transmission of maternal effects. Our experimental approach does not allow, however, 385 to discriminate whether this heritable or non-heritable transgenerational effects (sensu 386 Boyko and Kovalchuk, 2011) are prevailing in our case.

387 In conclusion, this work reports significant environmental maternal effects on 388 the germination time and the viability of seeds of a temperate conifer species. Although 389 different male genetic contributions may be also affecting germination, our results 390 suggest that environmental maternal effects are significant drivers of these highly 391 important adaptive traits in $P$. pinaster. Additionally, although germination timing was 392 highly influenced by the seed weight, seed weight differences between the two maternal environments were not enough to explain the observed differences in germination

394 timing. Our results indicate, thus, that other epigenetic mechanisms rather than the 395 maternal quantitative investment in seed size may be involved in the transmission of 396 this form of transgenerational plasticity. Genetic variation in the sensitivity to the 397 maternal environmental variation for both the timing of germination and the viability of 398 seeds constitute the basis for the evolution of these maternal effects as adaptive traits in 399 this Mediterranean pine species. 


\section{Acknowledgements}

402 This work was financed by the grants RTA2007-100, PSE310000, and AGL2010403 18724. L.S. was supported by a DOC-INIA grant. The two seed orchards were 404 established by the Forestry Research Center of Lourizán, Xunta de Galicia. We thank 405 Benito Santos, Raúl de la Mata, Patricia Martins Montse Peso, Oscar Vilariño, Bretema 406 Dorado, Fernando González, Rocío Huelga, Peregrina Méndez, Mercedes Vázquez for 407 their help in field and greenhouse sampling. Avelina González, Rocio Campanó and 408 Luz Pato are also acknowledged for their help in seed weight determinations and 409 germination surveys. We are also very grateful for the language edition by David Brown 410 and for the data and suggestions provided by Esther Merlo. Valuable comments by two 411 anonymous referees are also acknowledged.

\section{References}

414 Alboresi, A., Gestin, C., Leydecker, M.T., Bedu, M., Meyer, C., Truong, H.N., 2005. 415 Nitrate, a signal relieving seed dormancy in Arabidopsis. Plant Cell Environ. 28, $500-512$.

417 Alía, R., Martin, S., De Miguel, J., Galera, R., Agúndez, D., Gordo, J., Catalán, G., Gil, 418 L., 1996. Las regiones de procedencia de Pinus pinaster Ait. OA de Parques $419 \quad$ Nacionales. DGCONA, Madrid.

420 Andersson, B., 1994. Aftereffects of maternal environment on autumn frost hardiness in Pinus sylvestris seedlings in relation to cultivation techniques. Tree Physiol. 14, 313-322.

Baskin, C.C., Baskin, J.M., 1998. Seeds: ecology, biogeography and evolution of dormancy and germination. Academic Press, San Diego, CA. 
425 Bevington, J., 1986. Geographic differences in the seed germination of paper birch (Betula papyrifera). Am. J. Bot. 73, 564-573.

427

428

Biere, A., 1991. Parental effects in Lychnis-Flos-Cuculi. 1. Seed size, germination and seedling performance in a controlled environment. J. Evol. Biol. 4, 447-465.

Bossdorf, O., Arcuri, D., Richards, C.L., Pigliucci, M., 2009. Experimental alteration of DNA methylation affects the phenotypic plasticity of ecologically relevant traits in Arabidopsis thaliana. Evol. Ecol. 24, 541-553.

Boyko, A., Blevins, T., Yao, Y., Golubov, A., Bilichak, A., Ilnytskyy, Y., Hollander, J., Meins, F., Kovalchuk, I., 2010. Transgenerational adaptation of Arabidopsis to stress requires DNA methylation and the function of Dicer-like proteins. PLoS One 5, e9514.

Boyko, A., Kovalchuk, I., 2011. Genome instability and epigenetic modification heritable responses to environmental stress? . Current Opinion in Plant Biology $14,260-266$.

Castro, J., 2006. Short delay in timing of emergence determines establishment success in Pinus sylvestris across microhabitats. Ann. Bot. 98, 1233-1240.

Castro, J., Hódar, J.A., Gómez, J.M., 2006. Seed size, in: Basra, A.S. (Ed.), Handbook of seed science and technology. Haworth Press, New York, pp 397-428.

Climent, J., Aránzazu-Prada, M., Calama, R., Chambel, R., Sánchez-de-Ron, D., Alía, R., 2008. To grow or to seed: Ecotypic variation in reproductive allocation and cone production by young female Aleppo pine (Pinus halepensis, Pinaceae). Am. J. Bot. 95, 833-842.

Dolgosheina, E.V., Morin, R.D., Aksay, G., Sahinalp, S.C., Magrini, V., Mardis, E.R., Mattsson, J., Unrau, P.J., 2008. Conifers have a unique small RNA silencing signature. RNA 14, 1508-1515. 
450 Donohue, K., Dorn, L., Griffith, C., Kim, E., Aguilera, A., Polisetty, C.R., Schmitt, J., 2005. Environmental and genetic influences on the germination of Arabidopsis thaliana in the field. Evolution 59, 740-757.

Donohue, K., Heschel, M.S., Butler, C.M., Barua, D., Sharrock, R.A., Whitelam, G.C., Chiang, G.C.K., 2008. Diversification of phytochrome contributions to germination as a function of seed-maturation environment. New Phytol. 177, 367379.

Donohue, K., 2009. Completing the cycle: maternal effects as the missing link in plant life histories. Philos. Trans. Royal Soc. B 364, 1059-1074.

Donohue, K., Rubio de Casas, R., Burghardt, L., Kovach, K., Willis, C.G., 2010. Germination, postgermination adaptation, and species ecological ranges. Ann. Rev. Ecol. Evol. Syst. 41, 293-319.

Emberger, C., Gaussen, H., Kassas, M., dePhilippis, A., 1963. Bioclimatic map of the Mediterranean zone, explanatory notes. UNESCO-FAO, Paris.

Figueroa, R., Herms, D.A., Cardina, J., Doohan, D., 2010. Maternal environment effects on common groundsel (Senecio vulgaris) seed dormancy. Weed Sci. 58, 160-166.

Galloway, L.F., Etterson, J.R., 2007. Transgenerational plasticity is adaptive in the wild. Science 318, 1134-1136.

Gehring, M., Bubb, K.L., Henikoff, S., 2009. Extensive Demethylation of Repetitive Elements During Seed Development Underlies Gene Imprinting. Science 324, $1447-1451$.

González-Martínez, S.C., Mariette, S., Ribeiro, M.M., Burban, C., Raffin, A., Chambel, M.R., Ribeiro, C.A.M., Aguiar, A., Plomion, C., Alia, R., Gil, L., Vendramin, G.G., Kremer, A., 2004. Genetic resources in maritime pine (Pinus pinaster 
Aiton): molecular and quantitative measures of genetic variation and differentiation among maternal lineages. For. Ecol. Manage. 197, 103-115.

Jayawickrama, K.J.S., Jett, J.B., Mckeand, S.E., 1991. Rootstock effects in grafted conifers: a review. New Forests 5, 157-173.

Jensen, P.J., Makalowska, I., Altman, N., Fazio, G., Praul, C., Maximova, S.N., Crassweller, R.M., Travis, J.W., McNellis, T.W., 2010. Rootstock-regulated gene expression patterns in apple tree scions. Tree Genetic \& Genomes 6, 57-72.

Johnsen, O., Skroppa, T., Junttila, O., Daehlen, O.G., 1996. Influence of the female 482 flowering environment on autumn frost-hardiness of Picea abies progenies. Theor. App. Gen. 92, 797-802.

Johnsen, O., Fossdal, C.G., Nagy, N., Molmann, J., Daehlen, O.G., Skroppa, T., 2005. Climatic adaptation in Picea abies progenies is affected by the temperature during zygotic embryogenesis and seed maturation. Plant Cell Environ. 28, 1090-1102.

Keeley, J., Zedler, P., 1996. Evolution of life history in Pinus, in: Richardson, D. (Ed.), 488 Ecology and biogeography of Pinus. Cambridge University Press, Cape Town pp 219-250.

Lacey, E.P., 1996. Parental effects in Plantago lanceolata L .1. A growth chamber experiment to examine pre- and postzygotic temperature effects. Evolution 50, 865-878.

Lacey, E.P., Smith, S., Case, A.L., 1997. Parental effects on seed mass: Seed coat but not embryo/endosperm effects. Am. J. Bot. 84, 1617-1620.

Latzel, V., Klimesova, J., Hajek, T., Gomez, S., Smilauer, P., 2010. Maternal effects alter progeny's response to disturbance and nutrients in two Plantago species. Oikos 119, 1700-1710. 
Lindgren, D., Wei, R.P., 1994. Effects of maternal environment on mortality and growth in young Pinus sylvestris in field trials. Tree Physiol. 14, 323-327.

500 Linkies, A., Graeber, K., Knight, C., Leubner-Metzger, G., 2010. The evolution of seeds. New Phytol. 186, 817-831.

Littell, R.C., Milliken, G.A., Stroup, W.W., Wolfinger, R.D., Schabenberger, O., 2006. SAS System for mixed models, 2nd ed. SAS Institute, Cary, NC.

Miguel, C., Gonçalves, S., Tereso, S., Marum, L., Maroco, J., Margarida Oliveira, M., 2004. Somatic embryogenesis from 20 open-pollinated families of Portuguese plus trees of maritime pine. Plant Cell Tissue Organ Culture 76, 121-130.

Mirouze, M., Paszkowski, J., 2011. Epigenetic contribution to stress adaptation in plants. Current Opinion in Plant Biology 14, 267-274.

Moles, A.T., Ackerly, D.D., Webb, C.O., Tweddle, J.C., Dickie, J.B., Westoby, M., 2005. A brief history of seed size. Science $307,576-580$.

Mosher, R.A., Melnyk, C.W., 2010. siRNAs and DNA methylation: seedy epigenetics. Trends Plant Sci. 15, 204-210.

Nakabayashi, K., Okamoto, M., Koshiba, T., Kamiya, Y., Nambara, E., 2005. Genomewide profiling of stored mRNA in Arabidopsis thaliana seed germination: epigenetic and genetic regulation of transcription in seed. Plant J. 41, 697-709.

Ramirez-Valiente, J.A., Valladares, F., Gil, L., Aranda, I., 2009. Population differences in juvenile survival under increasing drought are mediated by seed size in cork oak (Quercus suber L.). For. Ecol. Manage. 257, 1676-1683.

519 Richards, C.L., Bossdorf, O., Verhoeven, K.J.F., 2010. Understanding natural epigenetic variation. New Phytol. 187, 562-564. 18, 209-235. 
523 Santos-del-Blanco, L., Notivol, Y., Zas, R., Chambel, M.R., Majada, J., Climent, J., 2010. Variation of early reproductive allocation in multi-site genetic trials of Maritime pine and Aleppo pine. For. Sys. 19, 381-392.

Stoehr, M.U., L'Hirondelle, S.J., Binder, W.D., Webber, J.E., 1998. Parental environment aftereffects on germination, growth, and adaptive traits in selected white spruce families. Can. J. For. Res. 28, 418-426.

Tarutani, Y., Shiba, H., Iwano, M., Kakizaki, T., Suzuki, G., Watanabe, M., Isogai, A., Takayama, S., 2010. Trans-acting small RNA determines dominance relationships in Brassica self-incompatibility. Nature 466, 983-U110.

Teixeira, F.K., Heredia, F., Sarazin, A., Roudier, F., Boccara, M., Ciaudo, C., Cruaud, C., Poulain, J., Berdasco, M., Fraga, M.F., Voinnet, O., Wincker, P., Esteller, M., Colot, V., 2009. A role for RNAi in the selective correction of DNA methylation defects. Science 323, 1600-1604.

Tielborger, K., Petru, M., 2010. An experimental test for effects of the maternal environment on delayed germination. J. Ecol. 98, 1216-1223.

Wagner, I., Simons, A.M., 2009. Divergent norms of reaction to temperature in germination characteristics among populations of the arctic-alpine annual,

541 Webber, J., Ott, P., Owens, J., Binder, W., 2005. Elevated temperature during reproductive development affects cone traits and progeny performance in Picea glauca x engelmannii complex. Tree Physiol. 25, 1219-1227.

544 Yakovlev, I.A., Fossdal, C.G., Johnsen, O., 2010. MicroRNAs, the epigenetic memory and climatic adaptation in Norway spruce. New Phytol. 187, 1154-1169. 
546 Zas, R., Merlo, E., Fernandez-Lopez, J., 2003. SYNCHRO: A SAS program for

547 analysing the floral phenological synchronisation in seed orchards. Silvae Genet. $52,212-215$.

549 Zas, R., Merlo, E., Fernandez-Lopez, J., 2004. Genotype x environment interaction in 550 maritime pine families in Galicia, northwest Spain. Silvae Genet. 53, 175-182.

551

552 
554 Table 1. Climatic, edaphic and dasometric characteristics of the two maternal 555 environments of contrasting site quality, the high (Sergude), and the low quality clonal 556 seed orchards (Monfero).

\begin{tabular}{lcc} 
& Monfero & Sergude \\
\hline Altitude $(\mathrm{m})$ & 615 & 258 \\
Mean annual temperature $\left({ }^{\circ} \mathrm{C}\right)$ & 10.6 & 13.2 \\
Maximum temperature $\left({ }^{\circ} \mathrm{C}\right)$ & 35.3 & 38.7 \\
Minimum temperature $\left({ }^{\circ} \mathrm{C}\right)$ & -8.0 & -4.7 \\
Mean temperature of the warmest month $\left({ }^{\circ} \mathrm{C}\right)$ & 15.5 & 19.2 \\
Mean temperature of the coldest month $\left({ }^{\circ} \mathrm{C}\right)$ & 5.9 & 7.8 \\
Number of frost-free months ${ }^{\text {a }}$ & 3 & 5 \\
Annual precipitation $\left(1 \mathrm{~m}^{-2}\right)$ & 1435 & 1445 \\
Daily average wind speed $\left(\mathrm{m} \mathrm{s}^{-1}\right)$ & 5.2 & 3.2 \\
Number of windy days per year ${ }^{\mathrm{b}}$ & 166 & 35 \\
Soil pH $\left(\mathrm{H}_{2} \mathrm{O} 1: 2.5\right)$ & 4.5 & 5.1 \\
Soil depth $(\mathrm{cm})$ & $45.1 \pm 3.2$ & $>120 \mathrm{~cm}$ \\
Tree age at sampling & 20 & 27 \\
Mean tree diameter at breast height $(\mathrm{cm})$ & $6.1 \pm 0.3$ & $20.9 \pm 0.6$ \\
Annual individual tree growth in basal area $\left(\mathrm{cm}^{2} \mathrm{yr}^{-1}\right)$ & $1.65 \pm 0.15$ & $13.6 \pm 0.8$ \\
Number of cones per tree at age 9 & $3.8 \pm 0.2$ & $76.5 \pm 11.0$ \\
Reproductive allocation $\left(\mathrm{cones} \mathrm{dm}^{-2}\right){ }^{\mathrm{c}}$ & $15.8 \pm 2.8$ & $47.8 \pm 4.1$ \\
\hline
\end{tabular}

$559{ }^{a}$ sensu Emberger et al. (1963) i.e. the period during which the average minimum

560 temperature is over $7^{\circ} \mathrm{C}$

$561{ }^{\mathrm{b}}$ average wind speed $>5 \mathrm{~m} \mathrm{~s}^{-1}$

$562{ }^{\mathrm{c}}$ Number of cones per unit of basal area at breast height (modified from Climent et al., $5632008)$ 
566 Table 2. Results of the generalized mixed models for the analysis of the proportion of

567 filled seeds and the germination rate of filled seeds. Degrees of freedom (DF) and $F$ -

568 ratios are shown for fixed effects; variance components (VarComp) and associated $\chi^{2}$

569 values showing their statistical significance are shown for random factors. Both seed

570 orchards have exactly the same genetic material, clonally replicated by grafting, and

571 follow the same spatial design. Significance $(P<0.05) P$ values are typed in bold.

572

\begin{tabular}{|c|c|c|c|c|c|c|}
\hline \multirow[b]{2}{*}{ Effect } & \multicolumn{3}{|c|}{ Filled seeds \% } & \multicolumn{3}{|c|}{ Germination \% } \\
\hline & $\begin{array}{c}\text { DF or } \\
\text { VarComp }\end{array}$ & $\begin{array}{c}F \text { or } \\
\chi^{2}\end{array}$ & $P$ value & $\begin{array}{c}\text { DF or } \\
\text { VarComp }\end{array}$ & $\begin{array}{c}F \text { or } \\
\chi^{2}\end{array}$ & $P$ value \\
\hline \multicolumn{7}{|l|}{ Fixed factors } \\
\hline Maternal environment [E] & 1,9 & 0.04 & 0.8542 & 1,9 & 5.48 & $\mathbf{0 , 0 4 3 9}$ \\
\hline $\operatorname{Block}(E)^{\mathrm{a}}$ & 15,68 & 1.09 & 0.3842 & 15,68 & 0.86 & 0.6722 \\
\hline \multicolumn{7}{|l|}{ Random factors } \\
\hline Mother genotype [G] & $0.01 \pm 0.11$ & 2.82 & 0.0465 & $0.02 \pm 0.16$ & 0.27 & 0.3017 \\
\hline $\mathrm{G} \times \mathrm{E}$ & $0.17 \pm 0.15$ & 2.12 & 0.0727 & $0.24 \pm 0.22$ & 1.97 & 0.0802 \\
\hline Ramet $[\mathrm{G} \times \mathrm{B}(\mathrm{E})]$ & $0.64 \pm 0.13$ & 1860.9 & $<0.0001$ & $0.86 \pm 0.18$ & 452.0 & $<0.0001$ \\
\hline
\end{tabular}

573

$574{ }^{a}$ Block was nested within seed orchards

575 
576 Table 3. Results of the general mixed models for the analysis of the emergence time.

577 Degrees of freedom (DF) and $F$-ratios are shown for fixed effects; variance components

578 (VarComp) and associated $\chi^{2}$ values showing their statistical significance are shown for

579 random factors. Both seed orchards have exactly the same genetic material, clonally

580 replicated by grafting, and follow the same spatial design. Significance $(P<0.05) P$

581 values are typed in bold.

582

\begin{tabular}{lccc}
\hline & \multicolumn{3}{c}{ Emergence time } \\
\cline { 2 - 4 } Effect & DF or & $F$ or & $P$ value \\
& VarComp & $\chi^{2}$ & \\
\hline Fixed factors & 1,67 & 378.18 & $<\mathbf{0 . 0 0 0 1}$ \\
Maternal environment [E] & 15,67 & 1.38 & 0.1832 \\
Block(E) ${ }^{\mathrm{a}}$ & 1,7201 & 64.32 & $<\mathbf{0 . 0 0 0 1}$ \\
Seed weight $[\mathrm{SW}]$ & 1,7201 & 37.55 & $<\mathbf{0 . 0 0 0 1}$ \\
SW $\times$ E & & & \\
Random factors & $5.8 \pm 5.7$ & 18.6 & $<\mathbf{0 . 0 0 0 1}$ \\
Mother genotype $[\mathrm{G}]$ & $7.7 \pm 4.8$ & 10.9 & $\mathbf{0 . 0 0 0 5}$ \\
G $\times$ E & $10.9 \pm 2.3$ & 123.4 & $<\mathbf{0 . 0 0 0 1}$ \\
Ramet $[\mathrm{G} \times \mathrm{B}(\mathrm{E})]$ & $3.4 \pm 0.6$ & 69.0 & $<\mathbf{0 . 0 0 0 1}$ \\
Cone $(\mathrm{E} \times \mathrm{G} \times \mathrm{B})^{\mathrm{a}}$ & $71.6 \pm 1.2$ & & \\
Residual & & & \\
\hline
\end{tabular}

583

$584{ }^{a}$ Block was nested within seed orchards, and cones were nested within ramets $[\mathrm{G} \times$

$585 \mathrm{~B}(\mathrm{E})]$

586

587

588 
592

593

594

595

596

597

598

599

600

601

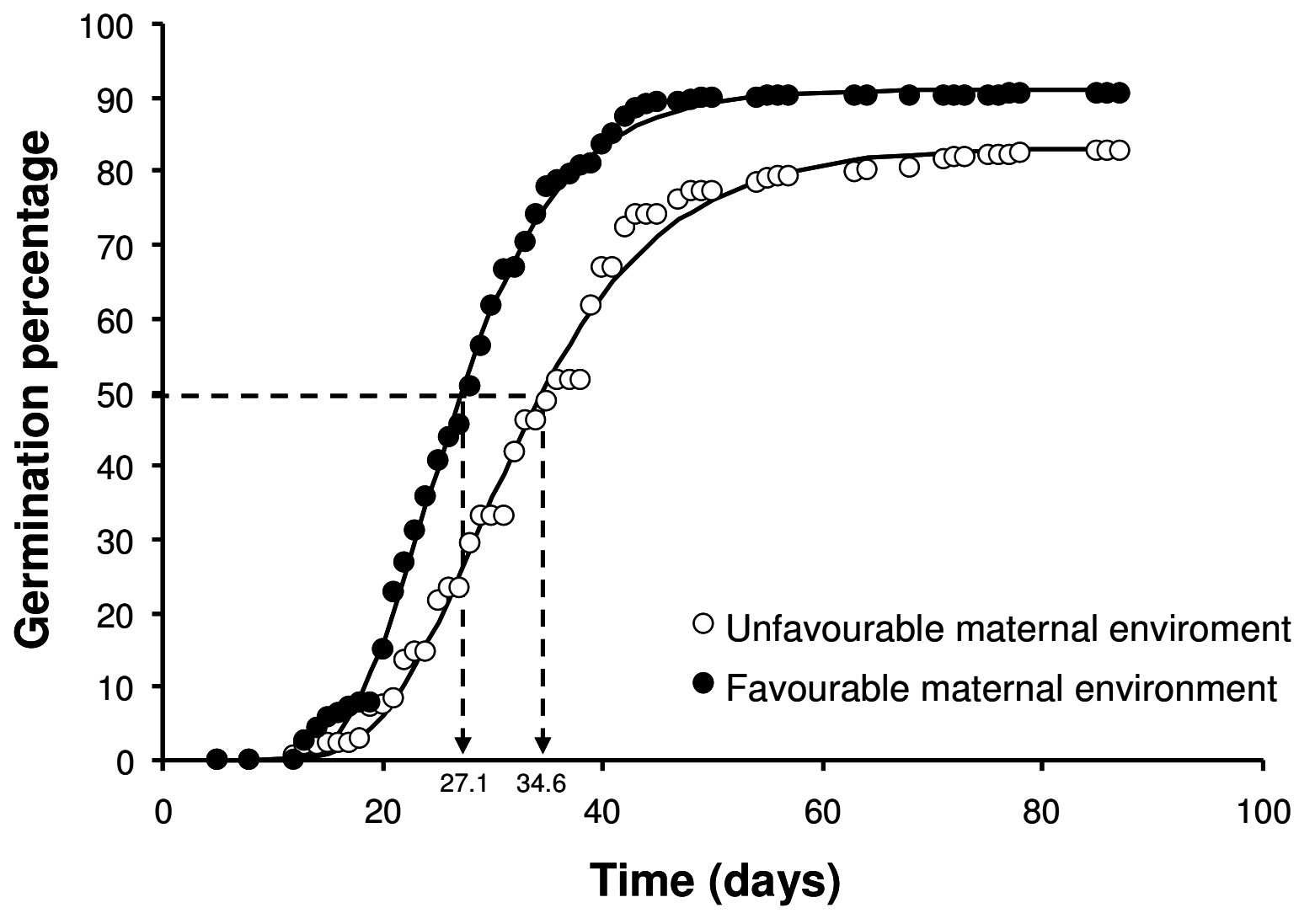

602

603

604 Figure 1. Germination progression of seeds collected in ten genotypes clonally

605 replicated in two contrasting environments, one especially favourable for pine growth

606 (black dots) and the other suffering multiple abiotic stresses (open circles). Dashed lines

607 denote the time needed for germination of the $50 \%$ of the sowed seeds. A Gompertz

608 model was fitted for each series. Sample size was 4628 and 4097 for the favourable and

609 unfavourable environments, respectively.

610 


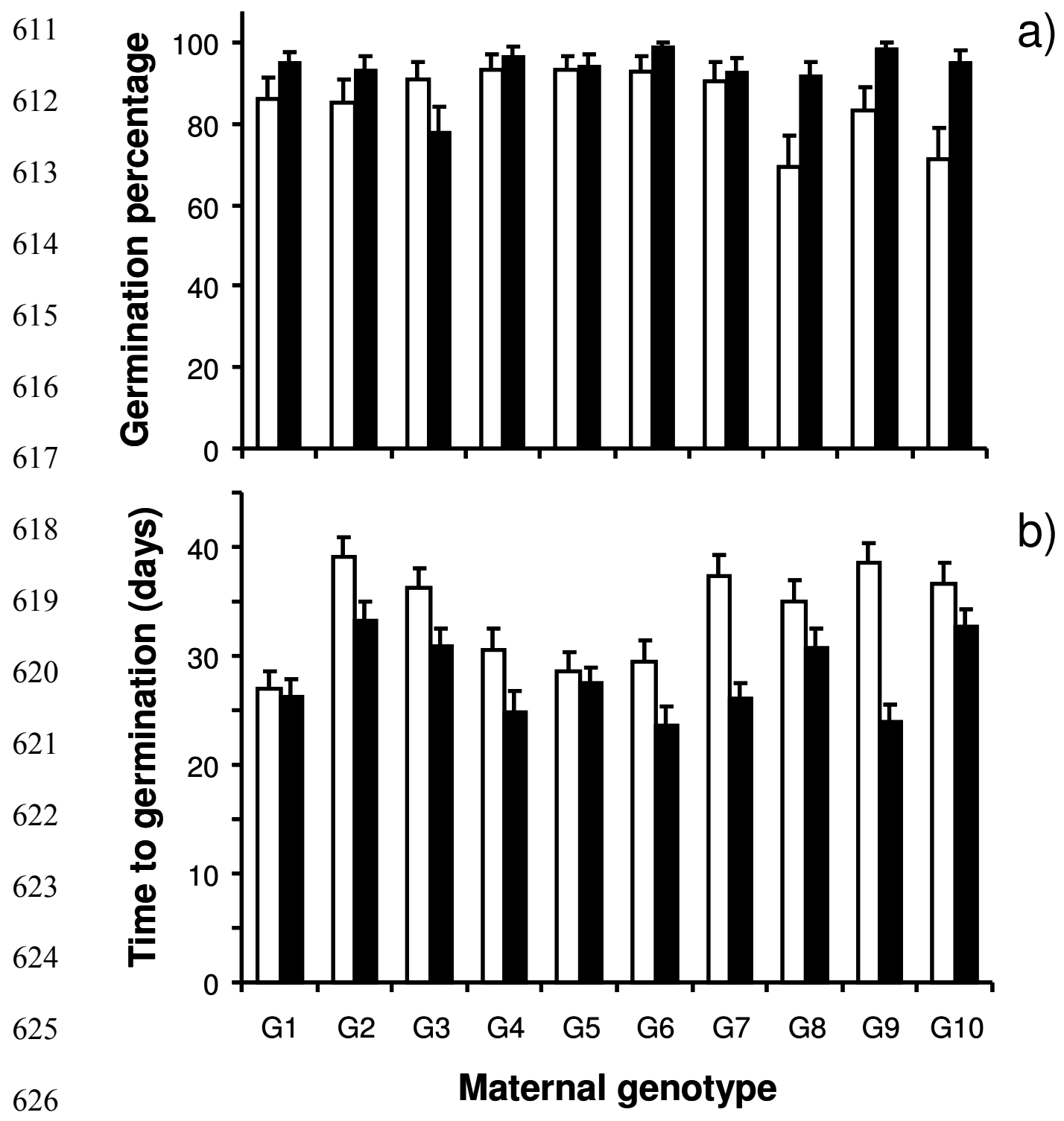

627

Unfavourable maternal environment

Favourable maternal environment

628

629 Figure 2. Germination percentage and time to emergence of seeds of $P$. pinaster

630 collected from ten maternal genotypes clonally replicated in two contrasting

631 environments, one especially favourable for pine growth (black bars) and the other

632 suffering multiple abiotic stresses (white bars). Means \pm s.e. are shown.

633 